\title{
IMPACT OF SERVICE AND FOOD QUALITY ON CUSTOMER SATISFACTION AMONG GENERATION Y FOR THE FAST FOOD RESTAURANT IN MALAYSIA
}

IntanMaizuraAbd Rashid, Muhammad Fazlee Sham Abdullah, BibiNorainiMohd Yusuf, MohdShahidanShaari School of Business Innovation and Technopreneurship, Universiti Malaysia Perlis intanmaizura@unimap.edu.my, fazleesham@unimap.edu.my, bibinoraini@unimap.edu.my, ABSTRACT shahidanshaari@unimap.edu.my

\begin{abstract}
The drive of this study is to contribute to the literature of service and food quality significance in fast food restaurant industry of Malaysia. The study is carrying out from the viewpoint of fast food restaurant industry and the customers' satisfaction among generation $Y$ in Malaysia. Three variables have been examined to demonstrate the significance of service quality and food quality on customer satisfaction. The outcomes ratify the importance of greater corresponding service and food standards in fast food restaurant industry. For food quality factor, all respondents are agreed with statement. Findings from 1000 respondents of Generation Y showed that two factors significantly influenced customer satisfaction. This research would be valuable in the improvement of a more comprehensive model to simplify a better understanding of customers' satisfaction among generation $Y$ on fast food restaurant in Malaysia; these findings would deliver a better comprehension of Malaysian customers' satisfaction and help design more effective marketing strategies.
\end{abstract}

\section{Indexing terms/Keywords}

Service Quality, Food Quality, Customer Satisfaction, Fast Food Restaurant, Franchising, Generation Y, Malaysia.

\section{Academic Discipline And Sub-Disciplines}

Marketing.

\section{SUBJECT CLASSIFICATION}

Marketing.

\section{Council for Innovative Research}

Peer Review Research Publishing System

\section{Journal: Journal of Social Sciences Research}

Vol. 5, No. 2

Jssreditor.cir@gmail.com

www.jssronline.com 


\section{INTRODUCTION}

The main focus of this article is to observe the relationship of service and food quality that importance to fast food restaurant industry amongst generation $Y$ studying adults in Malaysia. According to Teresa Sohoch (2012), the Generation $Y$ is born from 1980 to 1996. Generation $Y$ prefers flexible schedules and a better work - life balance. In addition, the Generation $Y$ is motivated, achievement - oriented and confident.

Thus, increasing personal income and urbanization of Malaysian population has createdchanges in the customer lifestyle. Customers are demanding for more variety andquality of food they consumed and are increasingly exposed to western food cultures.Customer are also experiencing a busier pace of life and creating demand for moreprocessed foods that are convenient to prepare rather than traditional cooking. Thesesituations make the customers to choose the fast food product in the market.

A fast food restaurant is characterized as quick services of franchise restaurant chain, which supplied the food quickly after ordering and minimal service offering for dining and takeout facilities. Fast food also refers to food that can be prepared and served quickly. Fast food restaurants usually have a walk up counter or drive-thru window where you order and pick up your food. Typically fast foods sold in a restaurant or store with preheated ingredients and serve to the customer in a packaged form for take away. Customers are generally price sensitive towards purchases of food but those from the middle to high income group are willing to pay more for the quality foods. According to Namita Jain (2010), fast food is often the default choice. Not only is it convenient and easy to grab, it's also tasty and cheap. And fast food joints also serve as great teenage hangout places. Fast food is also popular nowadays because it is cheap, fast, and tasty and advertisers make it seem healthy, so naturally it seems like a no brainer. Fast food restaurants are very popular because they serve filling foods that taste good and don't cost a lot of money.

However, fast food is usually cheap because it's often made with cheaper ingredients such as high fat meat, refined grains, and added sugar and fats, instead of nutritious foods such as lean meats, fresh fruits, and vegetables. Most fast food and restaurant chains offer free nutrition information online. Use a search engine to find the company's web page. There is usually a link to the nutrition section on the home page where you will find nutrition facts, including fat, cholesterol, sodium, protein, calories, and more. Many of these menus are now interactive as well, so you can preview your plate and modify it to be more nutritious. Take a look at this information to help you make healthier choices when eating out. If you don't have time or access to a computer, many restaurants offer nutrition pamphlets in the restaurant or have a way of pointing out healthier options on their menus.Based on the research conducted by ACNielsen Online Consumer Survey (2004) of fast food customers in Asia Pacific, Malaysia was ranked second place from the top 10 countries that are choosing fast food at least once a week with $59 \%$ after Hong Kong $61 \%$. This percentage is counted among of the 10 countries like Philippines, Singapore, Thailand, China, India, U.S, Australia and New Zealand. According to this study, it was found that there are five conditions that cause customers to choose the fast food:

1. The increase number of young people who did not like traditional way of cooking and accept the concept of fast food.

2. More affluent life from the environment.

3. Changing more lifestyle by eating out and has become a habit when have free time.

4. Changes to freedom and the role of women most of them work.

5. The change in family structure that has the force of high expenditure on food.

\section{Research Questions}

Based on the research background and to achieve the research objectives, this study seeks to address the following research questions :

1. What is the relationship between service quality and customer satisfaction?

2. What is the relationship between food quality and customer satisfaction?

\section{Research Objectives}

The objectives of this study are :

1. To describe the relationship between service quality and customer satisaction .

2. To determine the relationship between food quality and customer satisfaction .

\section{Significance of the study}

This research will show and expose on factors affecting consumer satisfaction on purchasing fast food and find out whether this factor are really affecting the consumer satisfaction on purchasing fast food. Franchise fast food right now is one of the good business opportunity and very competitive business in the global market. So, these businesses can be comparative between franchise companies with others company. Based on the results of this study is showed that the study should be done and it is consistent with the purpose of this study to understand about customers satisfaction of a society on the process of making the decision to choose a product or service.

\subsection{THE REVIEW OF LITERATURE}




\section{Definition of Term}

Some important terms appearing repeatedly in this study are briefly defined as follows:

- Purchase decision process by which consumers identify their needs, collect information, evaluate alternatives and make the purchase decision. These actions are determined by psychological and economic factors, and are influenced by environmental factors such as cultural, group, and social values.

- Franchising may be defined as the business opportunity by which the owner (producer or distributor) of a service or a trademarked product grants exclusive right to an individual for local distributor and sale of the service or product, and in return receives a payment or royalty and conformance to quality standards.

- Fast food means processed food prepared quickly by service providers and served by customer self-service. Fast food refers to food that can be prepared and served quickly. Fast food restaurants usually have a walk up counter or drive-thru windoy where you order and pick up your tood.

\subsection{Qustomer Satisfaction}

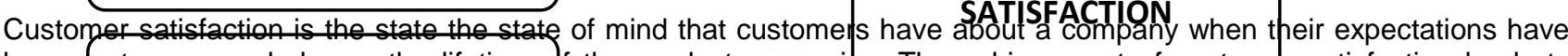
been fnet or exferododouexLITq lifetime of the product or servipe. The achievement of customer satisfaction leads to company loyalty and product repurchase. Eustomer satisfaction solars in their plevious studies, and it has been evallate in indifference manners. Research efforts on customer satisfaction can be categorized into two perspectives. Yi (1990) divided customer's satisfaction into reluctant satisfaction obtained from consumer experience and interim satisfaction in the middle of the evaluation process. Customer satisfaction as the function of expectations met and perception of discrepancies, suggesting a discrepancy paradigm. Customer satisfaction can be defined as a psychological response caused by experiences associated with the purchase of products or services.

\subsection{Fast Foods}

There is probably no universally accepted definition for the term "fast foods". Used loosely and in a wide sense, it can be taken to mean meals that are served on demand and made available in a short time. The fast pace of life today, combined with easy access to fast food and high exposure to fast food advertising and marketing, means fast foods are often chosen over foods that are prepared at home. Fast foods are often higher in fat, sugar and calories. Defining fast food or takeaway food outlets can be difficult. Much of the research and policy in this area only considers individual foods. The 'allowable proportion of unhealthy foods on a menu' for example, has not been defined and today traditional fast food outlets are broadening their menu to include healthy eating options. However, there is a growing interest in the use of zoning to restrict fast-food outlets to protect and promote community health. Ministry of Health of Malaysia has defined "fast foods" as "foods that are prepared in large quantities, following standardized procedures and served rapidly in restaurants commonly known as fast food restaurants, which usually advertise their services through the electronic and print media".

\subsection{Service Quality}

Service quality is the most researched area of services marketing (Fisk, et al., 1993). The concept was investigated in an extensive series of focus group interviews conducted by Parasuraman, et al. (1985). They conclude that service quality is founded on a comparison between what the customer feels should be offered and what is provided. Service quality often makes the difference between a successful and unsuccessful business. In fact, service quality has become the great differentiator, the most powerful competitive weapon and the most service organization possesses in business. Quality is defined as "conformance to specifications", but this phrase sometimes can be misleading. Quality as conformance to customer specification is the customers" definition of quality which is important to business to consider and deliver.

Researchers such as Garvin (1983), Holbrook and Cofman (1985) and Zeithaml (1996) have emphasized the difference between the objective and percieved quality. For example, Holbrook and Cofman (1985), noted that consumera do not use the term of quality in the same way as researchers and marketers, who define it conceptually. The conceptual meaning distinguishes between mechanistics and humanistic quality. Mechanistic (quality) involves an objective aspect or feature of thing or event while humanistic (quality) involves the subjective response of people to object and is therefore a highly relativistic phenomenon that differs between judges (Holbrook and Cofman, 1985).

\subsection{THEORETICAL FRAMEWORK AND RESEARCH METHODOLOGY}

\subsection{Theoretical Framework}




\subsection{Research Methodology}

This study is based on responses from 1,000 undergraduates at 20 of Malaysia institutions and universities. This research is quantitative, that is, according to Hopkins (2000) is to determine the relationship between one thing (an independent variable) and another (a dependent or outcome variable) in a population. On the other hand, the qualitative research is broadly based on the ideals of positivism where is assumes that "reality" is out there waiting to be discovered and that universal laws of nature operate according to rational, logical reasoning.In the research, all of responses or reply was limited to rating system on a five-point "Likert Scale" to measure the degree of factors affecting customer satisfaction on purchasing fast food.A total of 1,500 questionnaires were distributed among randomly the randomly selected respondents. However only 1,000 questionnaires were collected back, which made up 95\% of total questionnaires distributed were satisfactorily completed and tested by using the Statistical Package for Social Sciences (SPSS) software.The questionnaire was divided into three parts. All the questions were designed to be close-ended for easy analysis of the feedback. The question consists of three sections of questions. There are section $A$, section $B$ and section $C$, in the questionnaires. Section A, measurement used is nominal scale which is split data into mutual exclusive and collectively exhausted categories. It is designed to gather respondent demographic details such as gender, age, come from, course taking in Malaysia while section B is about factors of customer satisfaction in choosing fast food which respondents need to circle the appropriate answers provided. Section C measurement used is ordinal scale, the respondents" selection which measure two major items. The purpose of the questionnaires is to obtain the major information which is described in part $C$ such as food quality, and restaurant service. Scale that will be used is categorical scale in section $C$, which the respondents is asked to tick one answer from question 1 to question 21 at the space provided. The respondents were asked to indicate their degree of agreement or disagreement on several features, a five point lanker - type scale will be used with $1=$ "strongly disagree" to $5=$ "strongly agree". The populations of this study are among student that refers to generation $Y$ those studies in local universities in Malaysia.

\subsection{FINDINGS}

\subsection{Food Quality}

Figure 4.1 The food is served hot and fresh

The food is served hot and fresh

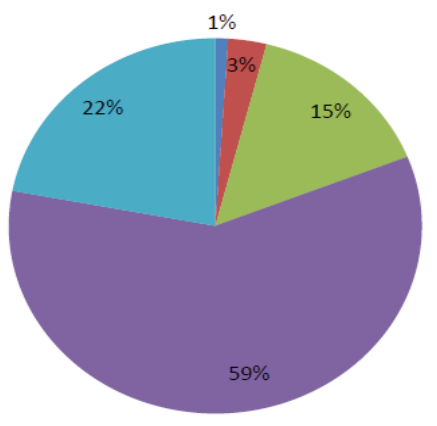

- Strongly disagree

- Disagree

neutral

agree

- Strongly agree

Figure 4.1 summarized the aspect of quality concern on the food is served hot and fresh. Total of $82 \%$ agreed that the food is served hot and fresh. Mean for this is 3.98 with standard deviation 0.765 .

Figure 4.2 The menu has a good variety of items

\section{The menu has a good variety of items}

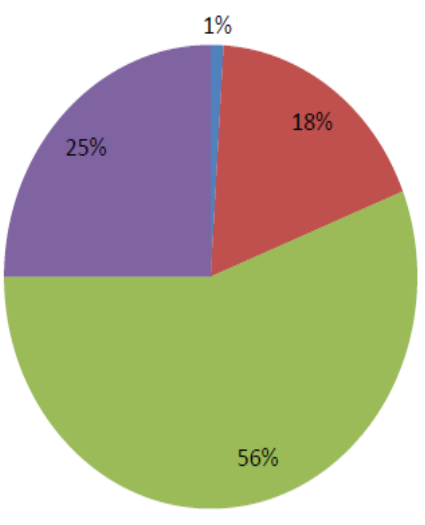

nisagree

neutral

Agree

- Strongly agree 
The figure above show the aspect of food quality of the menu has a good variety of items. From the table, $81 \%$ was agreed with this report tracked by $18 \%$ said it is neutral. The means of this question is 4.05 with standard deviation is 0.687 .

Figure 4.3 The service is excellent

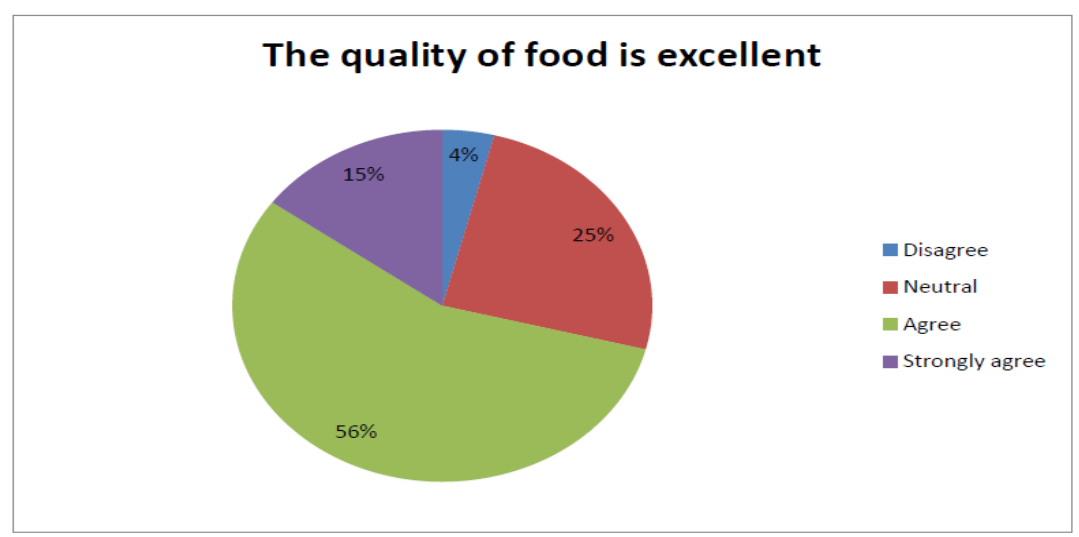

The figure summarized the aspect of food quality whether the quality of food is excellent. $71 \%$ agreed that quality of food is excellent. $25 \%$ said it is neutral and $4 \%$ was disagreed with this statement. Mean of the quality of food is excellent 3.82 and standard deviation is 0.730 .

Figure 4.4 The food is tasty and flavourful

The food is tasty and flavorful

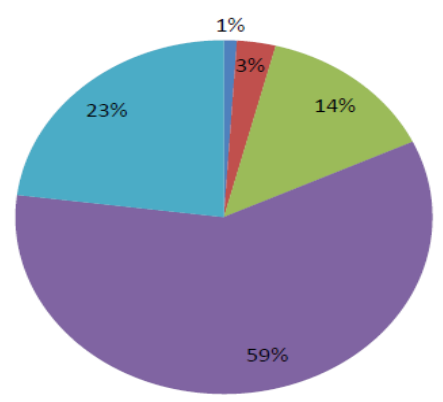

- Strongly disagree

nisagree

neutral

Agree

- Strongly agree

The figure brief on the food is tasty and flavorful. $82 \%$ of respondents agreed with this statement and 1400 respondents (14\%) with neutral. Only 400 respondents (4\%) not agreed with this statement. The means of this statement is 4.20 and standard deviation is 0.765 .

Figure 4.5 Fast food restaurant encourage people to eat their food

\section{Fast food restaurant encourage people to eat their food}

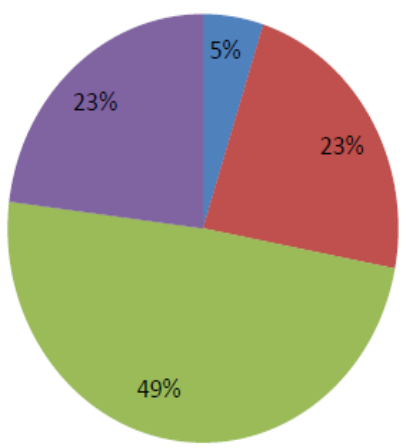


The figure shows the result fast food restaurants encourage people to eat their food. 720 respondents (72\%) was agreed with this statement, 230 respondents (23\%) think that is neutral and only 50 respondent out of 1000 disagreed with this statement. The means of total respondents is 3.90 with standard deviation is 0.810 .

\section{Summary of Dimensionin Food Quality}

As a conclusion, students observed the fast food restaurants' food quality based on the five dimensions which are the food is served hot and fresh (Mean 3.98 with standard deviation 0.765), the menu has a good variety of items (Mean 4.05 with standard deviation is 0.687$)$, excellent service $(M=3.82$; $S D=0.730)$, food is tasty and flavourful, the means of this statement is 4.20 and standard deviation is 0.765 and Fast food restaurant encourage people to eat their food dimensions $(\mathrm{M}=3.90 ; \mathrm{SD}=0.810)$. Tasty and flavourful of food was the most important element in how a customer perceived the food quality in relative to other dimensions. In addition, all the dimensions had standard deviations lower than 1.000 which means the students' perception of food quality towards these five dimensions was not widely scattered. However, the overall average mean score of 3.99 showed that the overall qualities provided by fast food restaurant in Malaysia are favourably perceived by their customers among generation $\mathrm{Y}$.

\subsection{Service Quality}

Figure 4.6 Order was correct and complete

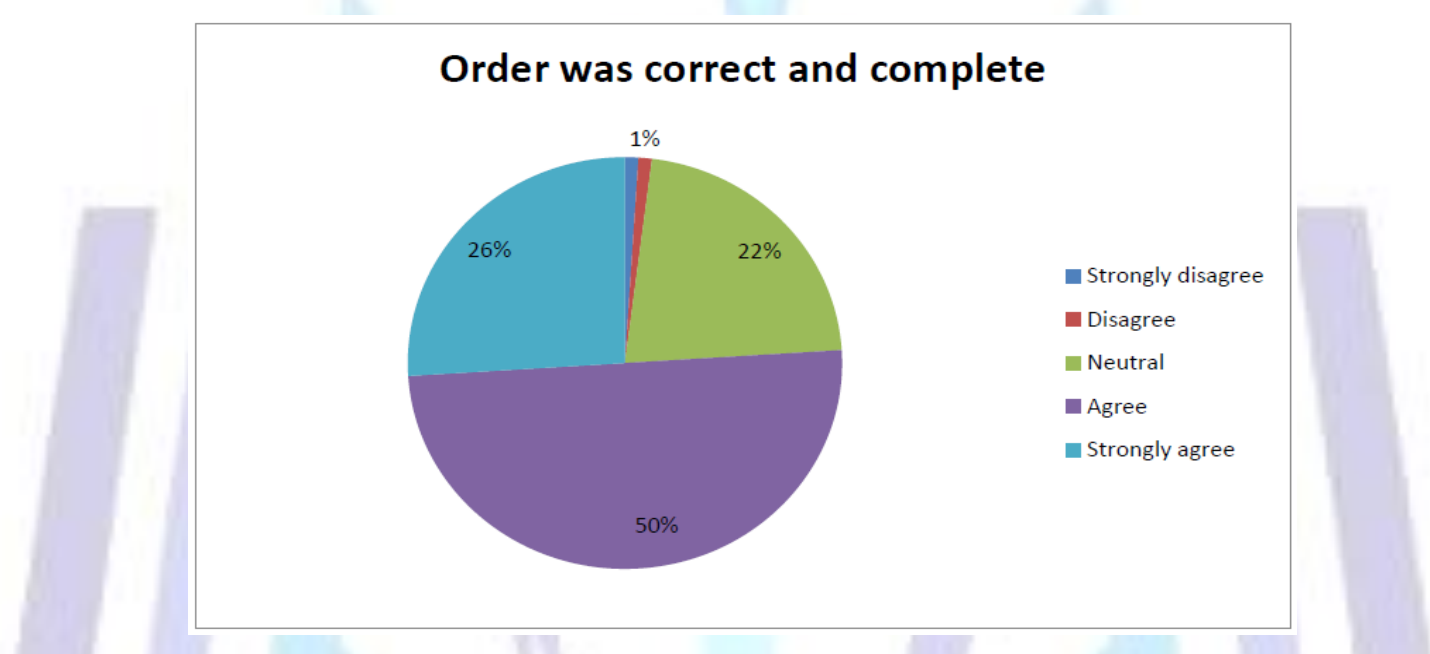

The figure above express the outcomes of restaurant service statement whether food order was correct and complete. It is about 760 respondents (76\%) was agreed that the food order was correct and complete. 220 respondents (22\%) is neutral reaction and 20 respondents (2\%) was disagreed with this statement. Means of total respondents is 3.99 with standard deviation is 0.785 .

Figure 4.7 I was served promptly

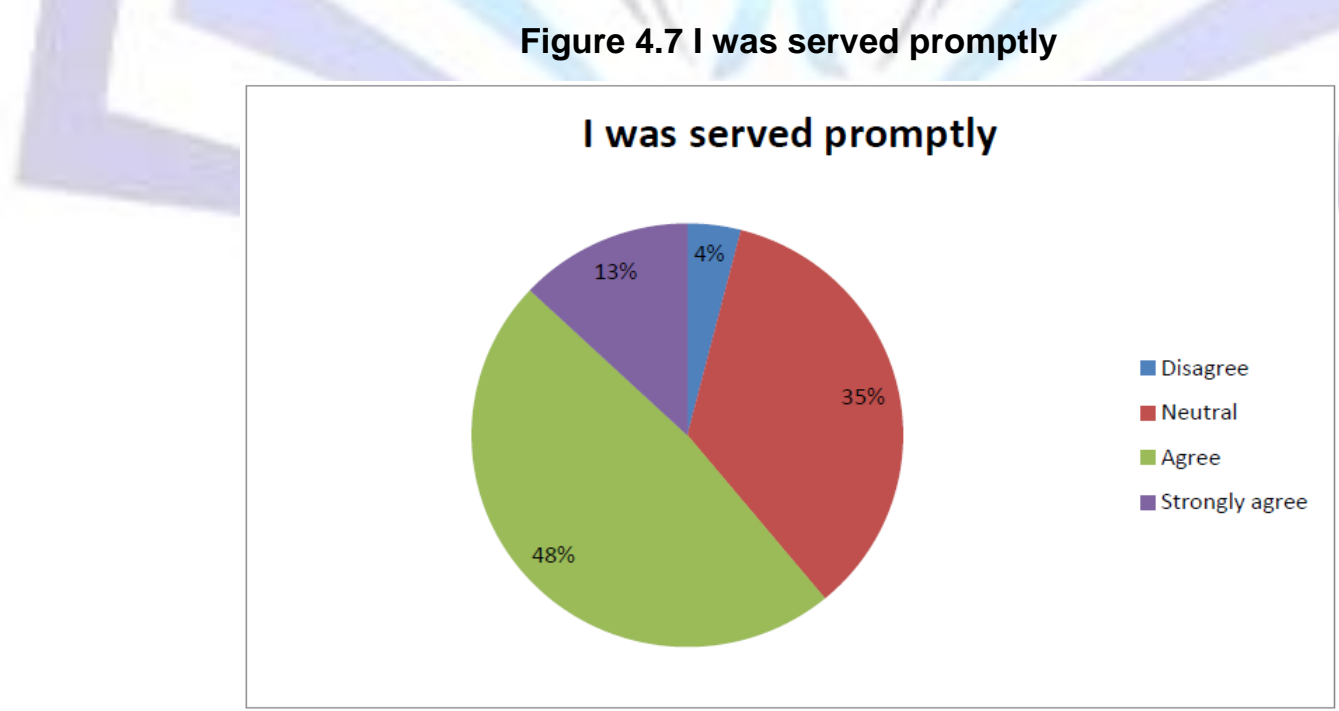

The figure above shows whether restaurant served promptly their service. 610 out of 1000 respondents $(61 \%)$ was agreed that they was served promptly. Next, 350 respondents (35\%) response it is neutral and 40 respondents disagreed with this statement. The means of all is 3.70 with standard deviation is 0.745 . 
Figure 4.8 Employees are patient when taking my order

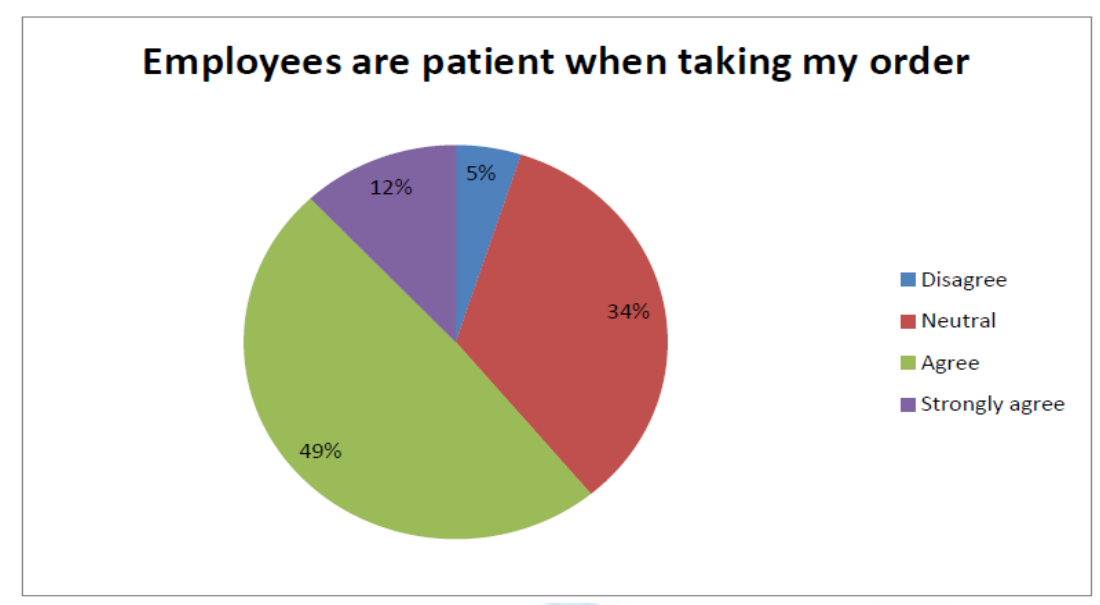

The figure shows the results of statement employees are patient when taking order. 610 respondents $(61 \%)$ was agreed that they received good treatment from employee. 340 respondents (34\%) said it is neutral and only 50 respondents (5\%) was disagreed with this statement. The means of this result is 3.68 and the standard deviation is 0.750 .

\section{Figure 4.9 Availability of sauces, utensils, napkins, etc. was good}

\section{Availability of sauces, utensils, napkins, etc} was good

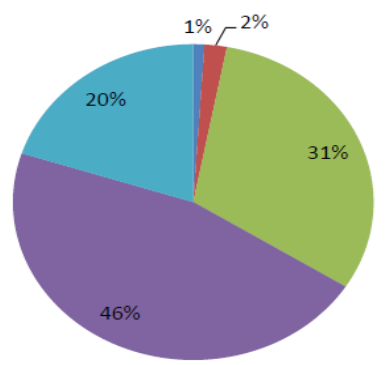

- Strongly disagree

nisagree

neutral

agree

antrongly agree

The above figure summarized on statement availability of sauces, utensils, napkins, etc was good. 660 out of 1000 respondents (66\%) agreed with this service provided. 310 respondents(31\%) just saying it is neutral and 30 respondents $(3 \%)$ disagreed. The total means of this statement is 3.82 and the standard deviation is 0.809 .

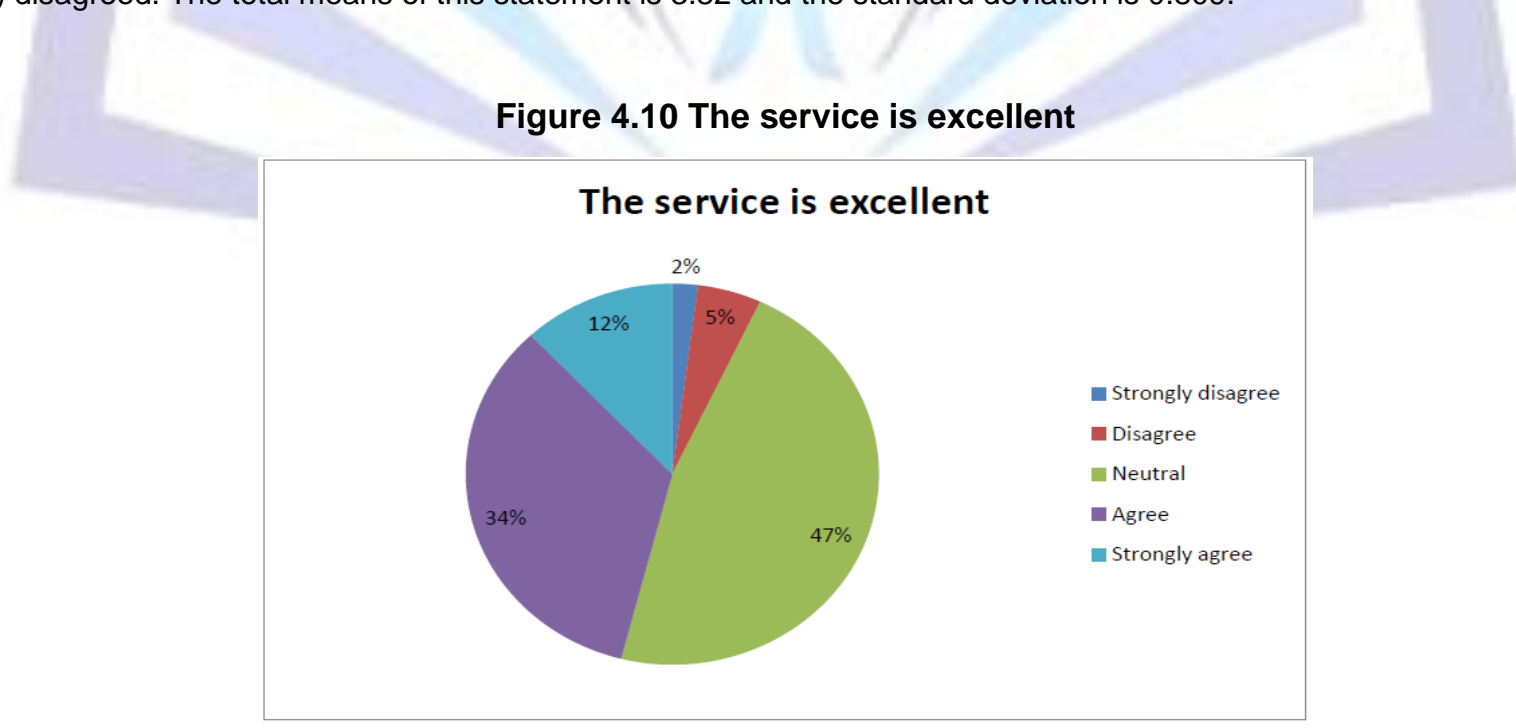

The figure 4.10 above shows the results whether the service is excellent. Based on the table 470 out of 1000 respondents $(47 \%)$ thick for neutral, otherwise 460 respondents (46\%) agreed with that fast food they have been visit provided excellent service. Respondents disagreed with this statement is $70(7 \%)$. Means for this statement question is 3.49 and standard deviation is 0.847 . 


\section{Summary of Dimension in Service Quality}

As a conclusion, students observed the fast food restaurants' food quality based on the five dimensions which are the order was correct and complete (Mean is 3.99 with standard deviation is 0.785 ), served promptly by the employees (Means is 3.70 with standard deviation 0.745), employees are patient when taking order $(M=3.68 ; S D=0.750)$, Availability of sauces, utensils, napkins, etc., The total means of this statement is 3.82 and the standard deviation is 0.809 and service dimensions $(M=3.49 ; \mathrm{SD}=0.847)$. Taking order was correct and complete was the most important element in how a customer perceived the service quality in relation to other dimensions. In addition, the overall average mean score of 3.736 showed that the overall services are favourably.

\subsection{Descriptive statistics and correlations}

Table 1.Descriptive statistics and correlations

\begin{tabular}{|ll|l|l|l|}
\hline & & $\mathrm{FQ}$ & $\mathrm{SQ}$ & $\mathrm{CS}$ \\
\hline Pearson & $\mathrm{FQ}$ & 1.000 & .554 & .746 \\
& $\mathrm{SQ}$ & .554 & 1.000 & .635 \\
& $\mathrm{CS}$ & .746 & .635 & 1.000 \\
\hline Sig. (1-tailed) & $\mathrm{FQ}$ & & .000 & .000 \\
& $\mathrm{SQ}$ & .000 &. & .000 \\
& $\mathrm{CS}$ & .000 & .000 &. \\
\hline
\end{tabular}

Table 1 shows the results of the Pearson correlation coefficient analysis on the associations between food quality and service quality on customer satisfaction. At the 0.01 significant levels, customers' satisfaction according to food quality had the strongest correlation with customer satisfaction where its " $r$ " value was 0.746 . Although service quality showed it had the lowest correlation but this is significant because of the $p$ value was smaller than 0.01 .

\subsection{Multiple regression results on dependent variable}

Table 2.Multiple regression results on dependent variable

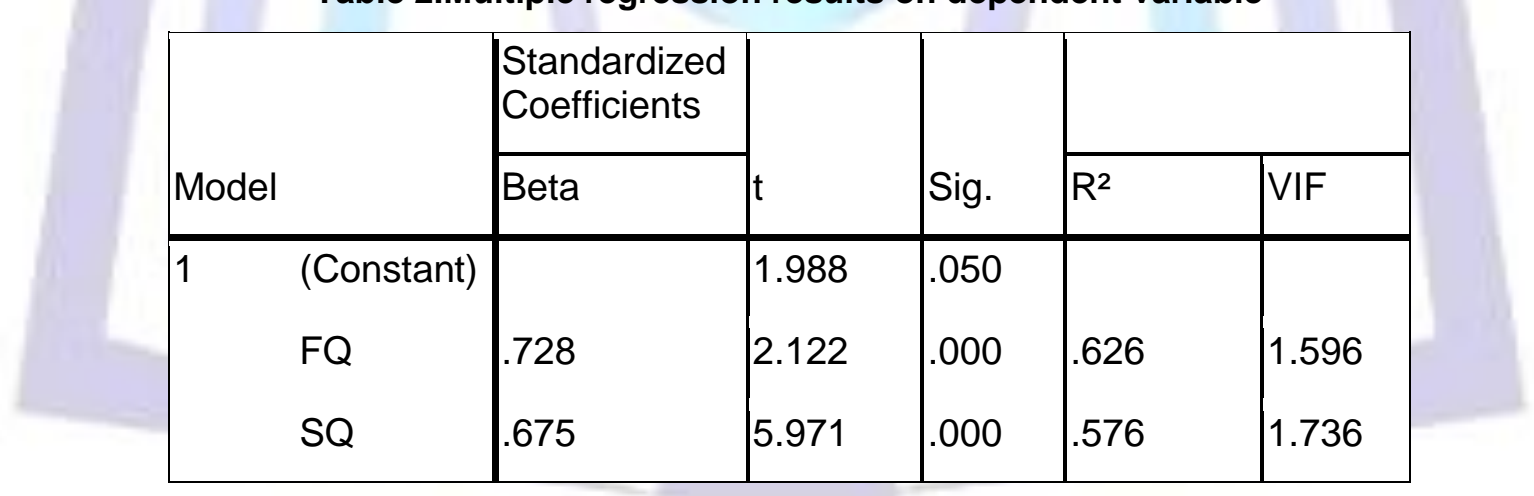

Multiple linear regressions were used to recognize the most main variable that influenced the customers' satisfaction of fast food restaurants. The significant level of 0.01 was used. As seen in Table 2, food quality (Beta $=0.728, p=0.000)$ was considered as a strong variable that significantly and positively influenced customer satisfaction among generation $Y$ in fast food restaurants. The value of $\mathrm{R}^{2}(0.626)$ implied that this model explained about $62.6 \%$ of the total variance in food quality. The independent variables included the two factors which were quality of food and quality of service. As shown in the table, all the two independent variables were positively and significantly affected on customer satisfaction. In overall, food quality was the key factor in deciding the customer satisfaction towards fast food restaurants in the context of Malaysian public university students.

\subsection{DISCUSSION AND CONCLUSION}

\subsection{Discussion}

The research finding according to the objectives of this study on factor affecting consumer satisfaction on purchasing fast food among universities"s student.

\subsubsection{Relationship between Demographic Characteristics and Customer Satisfaction}


The result for this relationship is presented as follows:

\subsubsection{Age}

Age limit has no relationship on customers" behavior on time of visit, number of members in a group people visiting the restaurant and amount of money spending to buy fast food. The way people live can determine by internal factors (personality, values, emotions and memory) and external factors (cultures, age, friends, family and subculture).

\subsubsection{Origin}

There is a relationship between consumer come from and customers" behavior in time of visit, amount of money spending on fast food and number of members in a group to visit. This finding support the understanding of differences among consumers in urban and suburban and the role of culture states that culture represents the common values, norms and behaviors of a particular group. Besides, culture is learned, shared, multidimensional and transmitted from one generation to the next generation. Understanding cultural differences is important in service marketing because of its effects on the ways that customers evaluate and use the services.

\subsubsection{Education Level}

There is no relationship between educstional level and customers" behavior in time spend, time of visit, amount of money spending on fast food and number of members in a group to visit. These findings conclude that education level influences what one can purchase by partially determining one"s income and occupation. It is also influences how one think, makes decisions and relates to other.

\subsubsection{Relationship between Food Quality and Customer Satisfaction}

There is a relationship between food quality and customer satisfaction in choosing to purchase fast food. This findings support with food quality of tasty and flavorful; and quality on food is served hot and fresh because on customer behavior by respondent's state that why they are choosing to buy fast food is because of it is quick and delicious.

\subsubsection{Relationship between Service Quality and Customer Satisfaction}

There is a relationship between services provide by fast food restaurant and customer satisfaction where customer almost agreed with food order was correct and complete. So, they were received excellent service also from menu on board was easy for them to read. It is relate to customer behaviour on the time that normally they buy or eating at fast food restaurant which is during lunch hour. Because of excellent service that restaurant provided customers are served in quickly time.

\subsection{Factors Affecting}

For food quality factor, all respondents are agreed with statement. Most of percentage that they agreed with all statement is above $50 \%$, where the highest agreed by respondents is the food is served hot and fresh ( $82 \%$ ). The next factor is restaurant service. Overall the respondents agreed with the service provided like $76 \%$ agreed that the food order was correct and complete. It shows that the service by fast food restaurant is good.

\subsection{Recommendation}

For further study on this topic, the researcher suggested that the study on factors affecting customer satisfaction on purchase fast food should be extended by comparing the results of this findings with the existing customer satisfaction studies by using the research conceptual behavior in term of frequency of re-visit at fast food restaurant.

\section{References}

1) ACNielsen Online Consumer Survey (2004),[Online]. Available WWW: http://www.acnielsen.fi/news/20051128.shtml

2) Anderson, E. W., \&Fornell, C. (1994). A customer satisfaction research prospectus. In Rust, R. T., \& Oliver, R. L. (Eds.), Service quality: new directions in theory and practice (pp. 241-268).

3) Boulding, W., Kalra, A., Staelin, R., \&Zeithaml, V. (1993). A dynamic process model of service quality: from expectations to behavioral intentions. Journal of Marketing Research, 30, 7-27.

4) Chu, M. L., Kuang, J. C., \& Chung, L. (2000). A look at fastfood competition in the Philippines. British Food Journal, 102(2), 122-133.

5) Fisk, R. P., Brown, S. W., and Bitner, Mary Jo. Tracking the Evolution of the Services Marketing Literature. Journal of Retailing 69[1], 61-103. 1993.

6) Garvin, D.A. (1983). Managing Quality.The Strategic and Competitive Edge. New York: Free Press.

7) Gilbert, G. R., Veloutsou, C., Goode, M. M. H., \&Moutinho, L. (2004). Measuring customer satisfaction in the fast food industry: a cross-national approach. The Journal of Services Marketing, 18(5), 371-383.

8) Holbrook, M. B. \&Corfman, K. P. (1985). Quality and value in the Consumption Experience: PhaedrusRides Again, "in perceived Quality, Jacob jacobyand Jerry Olson, eds. Lexington, MA: LaxingtonBooks, 31-57. 
9) Hooker, N., \& Caswell, J. (1999). Two case studies of food quality management systems. Journal of International Food and Agribusiness Marketing, 11, 1-10.

10) Hopkins, W.G. 2000. Sport science. Perspectives: research resources. Quantitative research design.[Online]. Available WWW: http://www.sportsci.org/jour/0001/wghdesign.html (Accessed 28 February 2006).

11) Lee, H., Lee, Y. K., \&Yoo, D. K. (2000). The determinants of perceived service quality and its relationship with satisfaction. Journal of Services Marketing, 14(3), 217-231.

12) Parasuraman, A., Zeithaml, V. and Malhotra, A. (2005), "E-S-Qual: a multiple-item scale forassessing electronic service quality”, Journal of Service Research, Vol. 7 No. 3, pp. 213 - 233.

13) Parasuraman (1985). Problems and Strategies in Service Marketing.Journal of Marketing. Vol.49, 33-46.

14) Parasuraman, A., Zeithaml, A. \& Berry, L.I (1985). A Conceptual Model of Service Quality and It's Implication for Future Research. Journal of Marketing. Vol. 49, No. 31, 41-50.

15) Robbins, S. P., DeCenzo, D. A., \& Coulter, M. (2011). Fundamentals of Management (7th ed.). Upper Saddle River, New Jersey: Prentice Hall.

16) Teresa Sohoch, J. D. (2012). Turning the ship around with a four-generation crew. Information Management, 25-29.

17) Yi, Y. (1990). A critical review of consumer satisfaction.In V. Zethiaml (Ed), Review of marketing (pp. 68-123). Chicago: American marketing Association.

18) Zeithaml, V.A., L.L. and Parasuraman, A. (1996, April). The Behavioral Consequences of Service Quality.Journal of Marketing. Vol. 60, 31-46. 